\title{
Proceeding
}

Performance Analysis Workshop, 2 - 5 April 2013, Alicante, Spain

\section{Video analysis as an instrument in juvenile soccer training}

\author{
DANIELA TURSI, SALVATORE NAPOLITANO , LORIS POLIDORO, GAETANO RAIOLA \\ Department of Human, Philosophical and Education Sciences, University of Salerno, Italy
}

\begin{abstract}
Tursi D, Napolitano S, Polidoro L, Raiola G. Video analysis as an instrument in juvenile soccer training. J. Hum. Sport Exerc. Vol. 8, No. Proc3, pp. S688-S693, 2013. In the Soccer, one of the most important variables to execute an effective action, it is the time needed by the athlete to complete his own movement (Nicoletti and Borghi,2007). The objective of this work is to verify if a systematic approach of "modeling" (Bandura, 1997) on a sample, using video analysis and field activities, lead to significant changes in the control group, for technical skills learning in children 9-10 years playing Soccer. Both groups were videotaped in the execution of three technical gestures (guide, control and shooting) and evaluated, through a grid created "ad hoc" by the technician, every three months. The data in the three phase evaluations (input, on going and final) and their analysis and comparison with data from the control group, showed a significant positive difference between the sample group and the control group (+7\%). In particular, the third phase showed a minor improvement (+2\%) compared to improvement between the first and second phase in the sample group $(+7.4 \%)$, while a substantial balance between the control group $(+2 \%)$. The experiment confirms the hypothesis and show the incidence of the use of video analysis as a tool for teaching and assessment of technical fundamentals in soccer game, giving great importance of "ideomotor" system to learn and refine the motor skills. Key words: SOCCER, TRAINING, IDEO-MOTOR, MODELING, YOUNG PLAYERS.
\end{abstract}

Corresponding author. Via Achille D'Orsi 13, Napoli, Italy.

E-mail: salvatorenapolitano1@alice.it

Performance Analysis Workshop, 2 - 5 April 2013, Alicante, Spain

JOURNAL OF HUMAN SPORT \& EXERCISE ISSN 1988-5202

(c) Faculty of Education. University of Alicante

doi:10.4100/jhse.2013.8.Proc3.15 


\section{INTRODUCTION}

One of the most important variables for action efficiency in soccer is the time an athlete takes to carry out a certain movement. (Nicoletti \& Borghi, 2007). On the qualitative aspect, the soccer is a sport where the time variable is very important in the control of motor learning process (Raiola, 2012). In fact, in soccer, it is particularly adequate considering development of motor capacity for technical characteristics, space and game rules, where time analysis, evaluation, elaboration and execution is limited with respect to other group sports (Schmidth \& Wrisberg, 2008). This is the reason why it can be considered particularly adequate regarding players 8-10 years of age (Winter, 1984), in order to gain and develop the specific techniques of the game. Furthermore, motor imagination (Sanders et al., 2004; Bandura, 1997) can favor qualitative motor learning if it is added in the weekly training program. The goal of the study is to compare two sample groups and to verify if the group who followed a training program in which filmed footage of themselves or of model motor executions was shown better learned specific techniques as compared to the group to whom no footage was shown. Very often, the new scientific discoveries are not transformed in innovation of training work out. This is still more truth if we analyzed the motor and sport train, where the routine doesn't, for the most part, based on assumed scientific, but on personal experiences or old customs. This void, that we could call "post-discovery", it is the space to which we will go to insert our research, consistent in to use the recent discoveries in neuro-cognitive-learning (Cattaneo \& Rizzolatti, 2009), in methodological routine for the sporting teaching in young players, as well as in to find an operational model way to analyze and to value the quality of the technical learning. In the world of the young soccer players is custom to use some simple technical- technical tests to be able to formulate some judgments and evaluations reliable to be inserted in the general planning of activities and to allow correctly the individual formative learning from who is appointed to the evaluation. As for other sporting disciplines also in the game of the Soccer the technical abilities of the athlete is held by different authors to depend on innate ability and not easily modifiable working on the learning, above all after a lot of experiences has been effected. Insofar, the work developed in the young players sector has a great importance in how much the children experience is still limited and in evolution period. Scientific evidences in produced literatures are not found concerning the application of the ideo-motor training by video with children and the evaluation through the performance analysis on the process of learning in 10 years old players.

\section{MATERIAL AND METHODS}

\section{Participants}

The study participants were composed by 20 young male players 9-10 years aged (pre-teen-agers) and divided into two homogenous groups (simple and control). All players had one year of experience in soccer in same team and with same coach.

All data were collected through an evaluation grids prepared "ad hoc" by the technical and researcher, based on the execution performed and on more common errors in young players

Procedures

The study is divided into three periods:

- In the first phase (entry) a pre-evaluation of the abilities, they have been conducted through some technical tests on the fundamental technique takes in object of the study (control the ball with the sole directed, guide the ball moving the ball with the sole, kick the ball with the toe) on 9-10 years old (pre-teen-agers) divided by the technician in two homogeneous groups (group champion $n=10$, 
control's group $n=10$ ). The technical gestures were videotaped and analyzed by the technician using an observation grid prepared ad hoc. This allowed us to have a reference point of departure for the entire research.

- In the second phase (after 3 months), the sample group $(n=10)$ after watching the projections of technical gestures to perform, through the viewing of videos showing a correct execution by a highlevel Soccer player. the sample group reproduced the same technical skills observed in videos during the workout, and they was been recorded by camera in the execution of customary three technical gestures, analyzing them performances by observation grid, and comparing the data with those of the first evaluation, as well as comparing data from the control group for initial assessment of the learning methodology, than comparing this methodology with the classical one. During this phase will be a verification to assess the evolution of technical learning process (on-going).

- The last phase (conclusive), we will see the final evaluation between the two groups to underline the incisiveness of the learning methodology and the validity of the evaluation system. The evaluation will be done by the same technician both in correlation model with young players, that players in first phase than in third phase, through a compared study with the executive model as well as of the progress at the end of the study.

The study protocol

The sample group will gather at the sports center 30 minutes prior to the control group. Filmed footage regarding three of the technical movements of the game will be shown:

1. Control of the ball: stopping with the sole of the foot (in jargon "sole stop").

2. Guiding the ball: Moving the ball with the sole.

3. Shooting: Kicking the ball.

The prearranged video clips are presented by the trainer, mainly focusing on the body segments relations and the most common execution mistakes. The first 5 minutes will be devoted to relaxation by listening to relaxing music and projected images, as the kids come to the field with a very high emotional charge that could adversely affect their ability to concentrate and focus. The next step is based on playing the video footage of the technical model in its entirety, inviting children to their highest attention while watching the video-clips in order to catch and learn as much information as possible. The last 5 minutes will be devoted to students. They will be asked to close their eyes and imagine themselves in executing the same gestures observed in the video. After having seen the footage, the group will carry out the same technical movements while themselves will be filmed for later evaluation.

\section{Materials}

Two cameras for recording the model in gestures executions and players performing same gestures. One laptop for analyze end prepare video lessons to show by projector to players during all meetings. Kinovea software was used for select most important part of videos and make a slow-motions of these ones.

\section{RESULTS}

After having analyzed the data from phase one, the groups were divided into two equal micro groups. Phase two involved highlighting the improvements of each single player of the sample group and comparing those results to those gathered before the start of the study (Figure 1). 


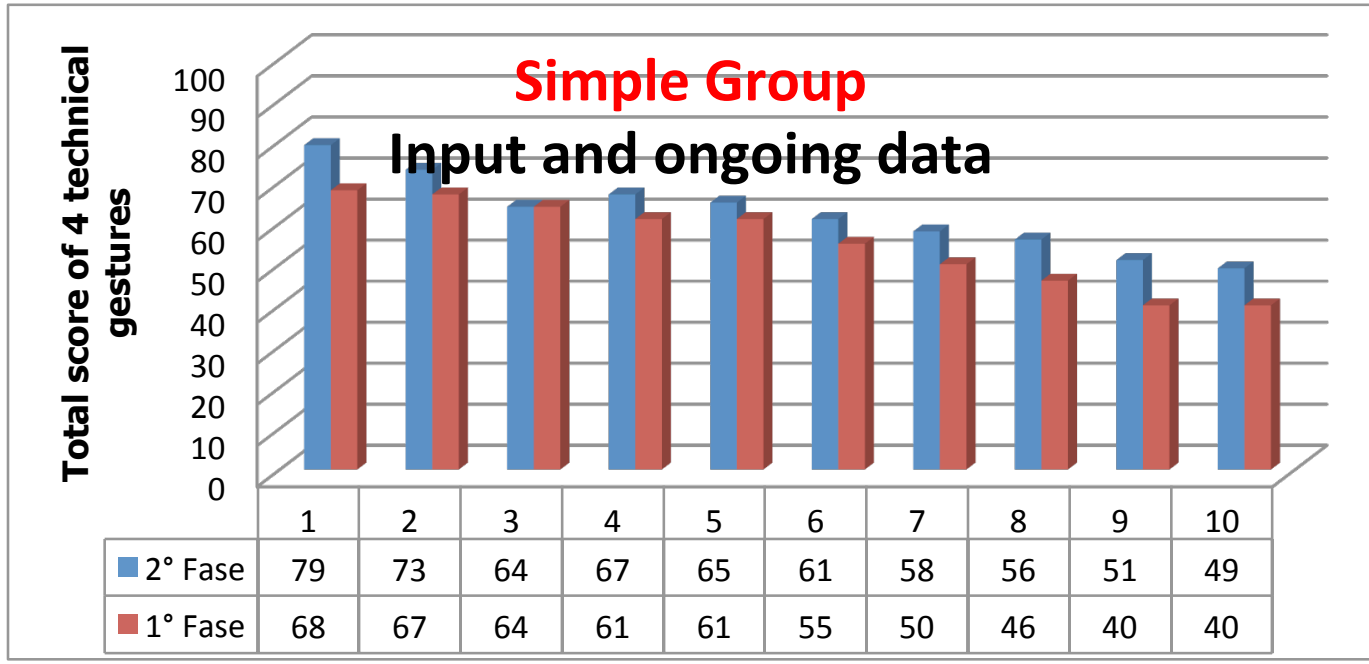

Figure 1. Comparison of the assessments in the sample group of observations in input and on-going with an average improvement of $+7.4 \%$

From the data we can note a net average improvement (Figure 2), of the sample group (7.2\%) with respect to the controlled group $(+2 \%)$, creating a hypothetical precautionary tendency for the third, and final phase of the study.
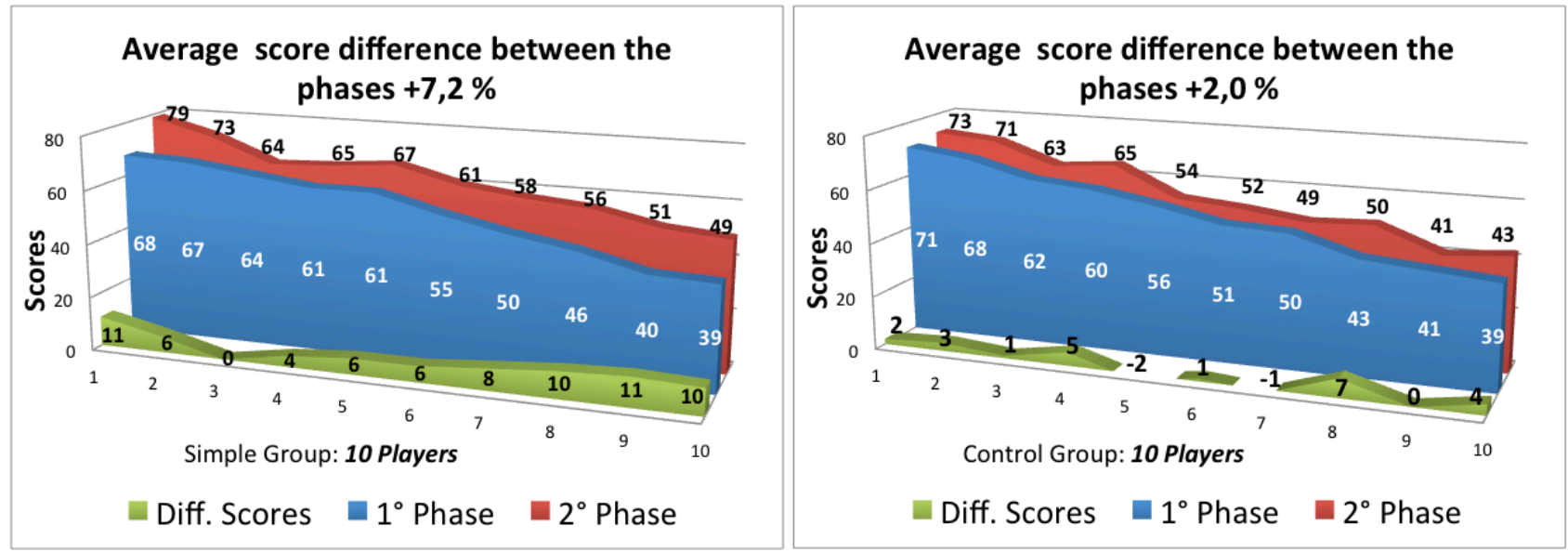

Figure 2. Comparison of the average score differences between the phases in two groups (+7.2 vs +2.0$)$

In particular, the second evaluation highlighted a significant improvement in those who held a good starting point $(11 \%)$. The data tends to suggest further technical improvement and perfection in subjects who showed considerable progress during phase two of the study, and a greater difference (Figure 3) between the sample group and the control group (>5\%). 


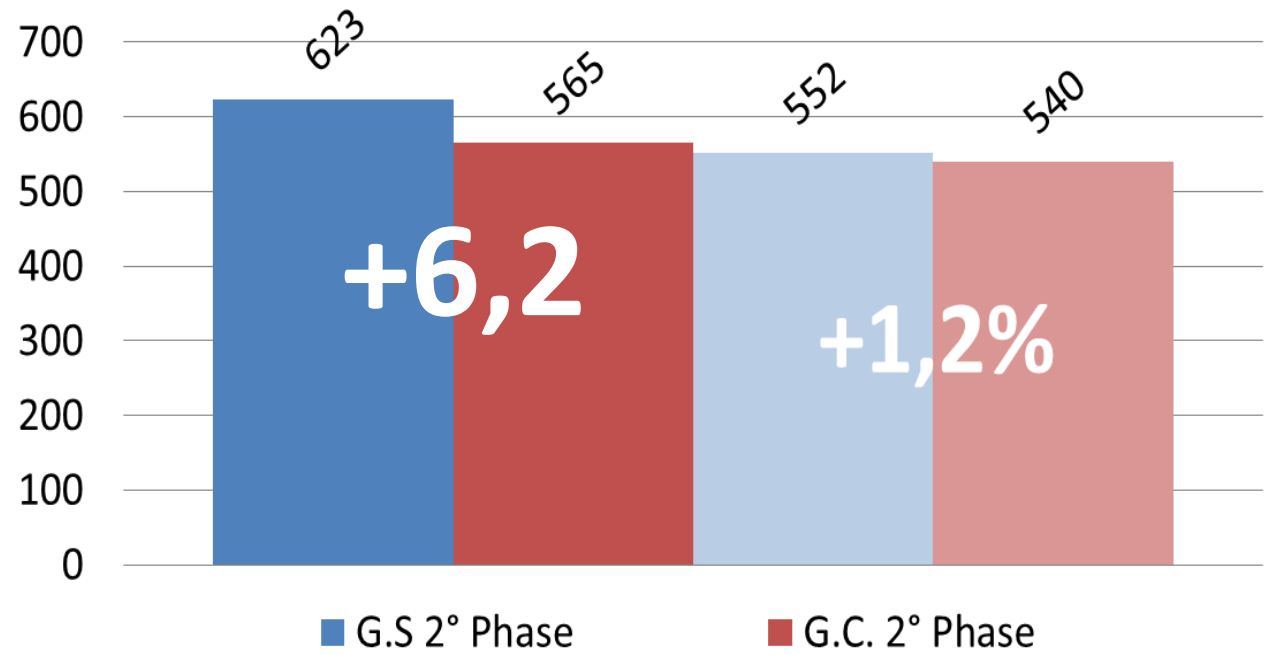

Figure 3. Comparison of the difference between the two groups in input and on-going showing an improvement of $+5 \%$

\section{DISCUSSION}

The process of teaching-learning is too often taken for granted, inevitable and automatic when a person shows to another what he knows or he is able to do. Scientific evidences shows that this superficial approach for the most of case, frustrates the efforts of the educators and creates frustration in the young players, making dissatisfied both the parts. So, once more, the circle virtuous theory-practice-theory making the learning process engaging and fascinating at the same time. From the data collected we can hypothesize greater incisiveness in the "video motory" system in those who possess good technical ability to begin with, and thus a lesser phase regarding correction and adjustment to technical movements after the visualization of the executive technical model.

\section{CONCLUSIONS}

The process of teaching-learning is too often taken for granted, inevitable and automatic when a person shows to another what he knows or he is able to do. Scientific evidences shows that this superficial approach for the most of case, frustrates the efforts of the educators and creates frustration in the young players, making dissatisfied both the parts. So, once more, the circle virtuous theory-practice-theory making the learning process engaging and fascinating at the same time. The study has the purpose to find a valid tool and a point of departure for trainers and researchers of the learning in young sport players group. The results show as this study can help the trainer to prepare the team in to sharpen the technical abilities and to analyze it in a "different" and "original" way, creating a methodological system that helps to improve in aware form the learning of the typical based technique technicians of a sport as the Soccer. The insertion in the technical planning of the video-analysis with educational finality, as an methodological approach, and as value system, can also stimulate the self valuation in the young players to considering it the true point of departure for the correct construction of the technical-motor knowledge. The narrowness of the work group (n.20) doesn't allow to generalize the results in statistic way, but surely it sets the bases of observation for the development of this kind of searches. 


\section{REFERENCES}

1. BANDURA A. Self-efficacy: The exercise of control. New York: W.H. Freeman. 1997.

2. CATTANEO L, RIZZOLATTI G. The Mirror Neuron System. Arch Neurol. 2009; 66(5):557-560.

3. DI TORE PA, POLIDORO L, BIANCHI F, RAIOLA G. Futsal didactics by video analysis education and training. Scientific Report Physical Educational and Sport. Pitesti: Romania. 2012.

4. NICOLETTI R, BORGHI AM. II controllo motorio. II Mulino. 2007.

5. RAIOLA G. La complessità dello studio in ambito sportivo. Pensa Editore. 2012.

6. SANDERS CW, SADOSKI M, BRAMSON R, WIPRUD R, VAN WALSUM K. Comparing the effects of physical practice and mental imagery rehearsal in learning basic surgical skills by medical students. Am J Obstet Gyen. 2004; 191(5):1811-4.

7. SCHMIDT RA, WIRSBERG C. Motor Learning and Performance: A Situation-Based Learning Approach. USA: Human Kinetics. 2008.

8. WINTER R. El test deportivo como método de control e investigación. In: Meinel K, Schnabel G. (Eds.). Teoria del Movimento. Roma: Società Stampa Sportiva.1984. 